\title{
Novel Spectrophotometric Method for the Determination of Azithromycin in Pharmaceutical Formulations based on its Charge Transfer Reaction with Quinalizarin
}

\author{
Carlos Eduardo R. de Paula, Vanessa G. K. Almeida and Ricardo J. Cassella* \\ Departamento de Química Analítica, Universidade Federal Fluminense, \\ 24020-141 Niterói-RJ, Brazil
}

\begin{abstract}
Neste trabalho é proposto um novo método para a determinação espectrofotométrica simples e rápida de azitromicina em formulações farmacêuticas. O método está baseado na reação de transferência de carga entre a azitromicina e a quinalizarina em meio de metanol. O efeito de diversas variáveis foi avaliado com o intuito de alcançar máxima sensibilidade analítica. A reação de transferência de carga foi caracterizada, sendo determinadas a estequiometria da reação, a absortividade molar aparente e a constante de associação. Melhores resultados foram obtidos em meio de metanol e com uma concentração de quinalizarina de $50 \mathrm{mg} \mathrm{L}^{-1}$. Nestas condições, o ânion radicalar (produto da reação de transferência de carga) foi formado imediatamente após a mistura dos reagentes, apresentando máxima absorção em $564 \mathrm{~nm}$. O método apresentou um limite de detecção de $0,35 \mathrm{mg} \mathrm{L}^{-1}$ e um limite de quantificação de $1,2 \mathrm{mg} \mathrm{L}^{-1}$, sendo aplicado com sucesso na determinação de azitromicina em três amostras de medicamentos comerciais contendo azitromicina.
\end{abstract}

This paper proposes a new method for simple and fast spectrophotometric determination of azithromycin in pharmaceutical formulations. The method is based on the charge transfer reaction between the azithromycin and quinalizarin in methanol medium. In order to achieve maximum sensitivity the effect of some chemical variables such as the type of solvent, reagent concentration and reaction time were evaluated. The reaction was characterized in terms of stability of the product formed and its stoichiometry, and the apparent molar absorptivity and association constant were derived. Best conditions for the analytical determination of azithromycin were observed in methanol medium with a quinalizarin concentration of $50 \mathrm{mg} \mathrm{L}^{-1}$. At these conditions, the radical anion (absorbing specie) was formed in the medium immediately after mixing of the reagents and showed maximum absorption at $564 \mathrm{~nm}$. The method presented a limit of detection of $0.35 \mathrm{mg} \mathrm{L}^{-1}$ and a limit of quantification of $1.2 \mathrm{mg} \mathrm{L}^{-1}$. It was successfully applied in the determination of azithromycin in three commercial pharmaceutical formulations of azithromycin and no matrix interferences were observed.

Keywords: charge transfer reaction, azithromycin, quinalizarin, spectrophotometry, pharmaceutical formulations

\section{Introduction}

Macrolide antibiotics are a class of compounds widely employed in human and veterinary medicine. They interfere in the synthesis of bacterial proteins resulting in a bacteriostatic effect on pathogens. ${ }^{1}$ In general, the structure of the macrolide antibiotics contains a macrocyclic lactone and a neutral sugar moiety attached to the lactone. Another important structural characteristic is the presence of other sugar moiety containing a dimethylamine group, which

*e-mail: cassella@vm.uff.br confers to the macrolides a basic behavior ${ }^{2}$ and makes them a potential n-electron donating substances. One of the most important members of this class is the azithromycin (Figure 1), which has been used as antibiotic in the human medicine for the treatment or prophylaxis of a number of health problems such as ear, lung, skin, and throat infections, ${ }^{3,4}$ veneral disease, ${ }^{5}$ pneumonia, ${ }^{6}$ toxoplasmosis ${ }^{7}$ and opportunistic diseases in patients with AIDS. ${ }^{8}$

Several analytical methods can be found in the literature for the azithromycin determination in different kinds of samples. Undoubtedly, high performance liquid chromatography (HPLC) with different detectors is the 
most employed technique for this purpose. Hence, methods based on HPLC with electrochemical, ${ }^{9,10}$ fluorimetric (with pre-column derivatization $)^{11,12}$ and mass spectrometric ${ }^{13,14}$ detection were already reported. On the other hand, the development of HPLC methods with UV detection is not a common subject because of the extremely low absorption capacity of the azithromycin in this spectral range. Nevertheless, Zubata et al. ${ }^{15}$ proposed a simple and lowsensitivity methodology for the azithromycin determination in pharmaceuticals using this approach.

Other analytical techniques also employed for azithromycin determination were voltammetry, ${ }^{16}$ amperometry, ${ }^{17}$ spectrofluorimetry, ${ }^{18}$ chemiluminescence ${ }^{19}$ and spectrophotometry. ${ }^{20-24}$ Although the low cost and simplicity of molecular absorption spectrophotometry only few papers related the use of this technique for azithromycin determination. In this field, Rachidi et al. ${ }^{20}$ proposed a method based on the extraction of the ionic-pair formed between azithromycin and Mo(IV)-SCN complex with dichloroethane. The measurements were performed at $469 \mathrm{~nm}$ against a blank solution prepared analogously to the standard solutions. The greatest inconvenient of the method was the excessive handling of the samples and the long time required to complete the whole procedure.

Sultana et al. ${ }^{21}$ studied the degradation of the azithromycin in strong acidic and alkaline media. Applying these treatments, the authors converted the azythomycin in a specie with higher absorbing capacity, making possible to perform its determination in the samples. Maximum absorption of the product was verified at $482 \mathrm{~nm}$ when a concentrated solution of $\mathrm{H}_{2} \mathrm{SO}_{4}$ was employed, while maximum absorption at $215 \mathrm{~nm}$ was observed for the product obtained in basic medium $\left(0.2 \mathrm{~mol} \mathrm{~L}^{-1} \mathrm{NaOH}\right)$. In both cases, the samples were heated at $60{ }^{\circ} \mathrm{C}$ for $30 \mathrm{~min}$ to achieve quantitative conversion of the azithromycin. Again, the excessive handling of samples and standard solutions was necessary to achieve a suitable sensitivity, making the analytical procedure laborious and time-consuming.

The method developed by Walash et al. ${ }^{22}$ was based on the formation of binary complexes between the macrolide antibiotics and eosin $Y$ in aqueous buffered medium at pH3.0. At this condition, binary complexes presented strong absorption in the range of 542-544 $\mathrm{nm}$. The procedure was applied in the determination of azithromycin, erythromycin, roxithromycin and clarithromycin in commercial medicines.

In spite of the fact that charge transfer reactions have been extensively employed in the development of spectrophotometric analytical methodologies applied to several drugs, ${ }^{25-32}$ only two works ${ }^{23,24}$ demonstrated the usefulness of such reactions in the azithromycin determination. Kelani et al. ${ }^{23}$ utilized the reagent DDQ (2,3-dichloro-5,6-dicyano-p-benzoquinone) as acceptor for the determination of various n-electron donating substances (azithromycin among them). Maximum sensitivity was obtained at $588 \mathrm{~nm}$ for all drugs tested, indicating that the product formed from the charge transfer reactions, in all cases, was the same. Huang et al. ${ }^{24}$ employed other two reagents, 7,7,8,8-tetracyanoquinodimethane (TCNQ) and chloranilic acid (CL), for the azithromycin spectrophotometric quantification in pharmaceuticals. After reacting with the azithromycin, both reagents produced substances (charge transfer complexes) that absorbed radiation at 743 and $842 \mathrm{~nm}$, respectively.

The goal of this work was to develop a simple, low-cost and efficient method for azithromycin determination in pharmaceutical formulations exploring, for the first time, its charge transfer reaction with quinalizarin. Secondly, this work aimed to evaluate and characterize such reaction, since quinalizarin was never employed for this task.

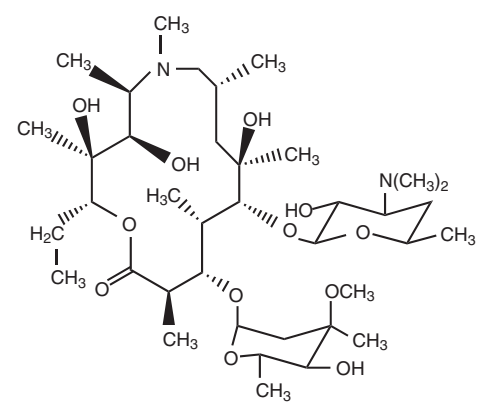

Figure 1. Structure of the azithromycin.

\section{Experimental}

\section{Apparatus}

All absorbance spectra were obtained with a Femto 800 XI (São Paulo, Brazil) spectrophotometer with a nominal resolution of $1 \mathrm{~nm}$ and a standard glass cuvette of $10 \mathrm{~mm}$ optical path. The spectrophotometer was coupled to a PC for data acquisition and treatment.

Infrared spectra were recorded with a Fourier transform spectrometer furnished by ABB (Zurich, Switzerland), model FTLA 2000. All spectra recorded in this work were an average of 16 accumulated scans with a nominal resolution of $4 \mathrm{~cm}^{-1}$.

An AND (Tokyo, Japan), model GR-202, analytical balance with a precision of $0.01 \mathrm{mg}$ was employed in all steps of the work.

\section{Reagents and solutions}

All solvents (dimethyl sulfoxide, methanol, ethanol, acetone and acetonitrile) used in this work were of 
HPLC grade and were supplied by Tedia (São Paulo, Brazil). Quinalizarin (1,2,3,4-hydroxyantraquinone) was of analytical grade and provided by Acros Organics (St. Louis, USA).

A $1000 \mathrm{mg} \mathrm{L}^{-1}$ standard stock solution of azithromycin was prepared by simple dissolution of $10.48 \mathrm{mg}$ of the pharmaceutical grade drug (di-hydrate form), furnished by Pharma Nostra (Rio de Janeiro, Brazil), in approximately $5.0 \mathrm{~mL}$ of methanol and further dilution to $10.00 \mathrm{~mL}$ with the same solvent in a volumetric flask. This solution was prepared daily since it was unstable after $24 \mathrm{~h}$ even when kept in the refrigerator. Working standard solutions were prepared from suitable dilution of the standard stock solution.

Quinalizarin (1,2,3,4-hydroxyantraquinone) solution with $500 \mathrm{mg} \mathrm{L}^{-1}$ was prepared by dissolving $25.0 \mathrm{mg}$ of the reagent, furnished by Vetec (Rio de Janeiro, Brazil), in approximately $25.0 \mathrm{~mL}$ of dimethyl sulfoxide (DMSO). After obtaining a solid-free solution, it was transferred to a $50.00 \mathrm{~mL}$ volumetric flask and the volume was completed to the mark with DMSO. This solution was stable for one week, at least.

\section{Construction of calibration curves}

Aliquots of methanol solutions containing known amounts of the drug were transferred to separated $25.00 \mathrm{~mL}$ volumetric flasks. To each flask $2.50 \mathrm{~mL}$ of the $500 \mathrm{mg} \mathrm{L}^{-1}$ quinalizarin solution was added. Afterwards, the obtained mixture was shaken in order to promote the reaction and the volume was completed to the mark with methanol. The absorbance of this final solution was measured at $564 \mathrm{~nm}$ against a blank containing only the quinalizarin reagent.

\section{Sample preparation and measurement}

After measuring the mass of each tablet individually (approximately $625 \mathrm{mg}$ each one), the whole blister content (three tablets) was weighed and finely powdered using an agate mortar. Then, a $50.0 \mathrm{mg}$ portion of the powdered sample was accurately weighed and exactly $25.0 \mathrm{~mL}$ of methanol was added. The mixture obtained was shaken for $5 \mathrm{~min}$ and then filtered through a PTFE membrane filter with $0.2 \mu \mathrm{m}$ pore diameter. Exactly $250 \mu \mathrm{L}$ of the filtrate and $2.50 \mathrm{~mL}$ of quinalizarin solution were transferred to a $25.00 \mathrm{~mL}$ volumetric flask, the volume was completed to the mark with methanol and the absorbance was measured at $564 \mathrm{~nm}$ against a reagent blank solution.

In the recovery test, the same procedure was adopted. However, in this experiment, a known mass (100.0 or $200.0 \mathrm{mg}$ ) of the solid standard azithromycin was added to the mortar during sample powdering.
The developed procedure was applied to the analysis of three commercial samples of different manufacturers, which were purchased in local markets in packages with three tablets containing a reported amount of $500 \mathrm{mg}$ of azithromicyn per tablet.

\section{Infrared spectra}

Infrared spectra of the quinalizarin, azithromycin and reaction product were recorded as potassium bromide pellets. For this purpose, approximately $10 \mathrm{mg}$ of each compound was mixed with $100 \mathrm{mg}$ of $\mathrm{KBr}$ and pressurized to obtain a pellet. Then, the pellet was transferred to the spectrometer and the spectra were recorded in the range of $4000-400 \mathrm{~cm}^{-1}$ with a nominal resolution of $4 \mathrm{~cm}^{-1}$.

The reaction product was obtained from a methanol solution containing $200 \mathrm{mg} \mathrm{L}^{-1}$ azithomycin and $50 \mathrm{mg} \mathrm{L}^{-1}$ quinalizarin. After obtaining a clear solution, the solvent (methanol) was evaporated at low pressure and temperature and the remaining solid was used for $\mathrm{KBr}$ pellet preparation and posterior infrared spectrum recording.

\section{Results and Discussion}

The study and development of the method for the determination of azithromycin in pharmaceutical formulations, exploring its charge transfer reaction with quinalizarin, was performed through two steps: $(i)$ optimization of the experimental conditions in order to achieve both maximum sensitivity and selectivity. This step comprised the evaluation of the effect of the solvent nature, investigation of the influence of the reagent concentration and evaluation of the time required to complete the reaction and; (ii) study and characterization of the reaction, which was carried out by the evaluation of the reaction stoichiometry (Job's continuous variation method), calculation of the association constant and molar absorptivity in methanol medium and the verification of the proposed reaction mechanism.

\section{Evaluation of the effect of the solvent nature}

The first parameter evaluated in the optimization of the experimental conditions was the nature of the solvent employed. The solvent plays an important role in some charge transfer reactions, since it must be able to facilitate the total charge transfer and then allow the complex dissociation and stabilization of the radical anion formed, which is the absorbing specie. According to the literature, solvents with high dielectric constant are more effective to execute this task. ${ }^{23,24}$ Taking this fact into account, water 
would be an excellent solvent for the procedure. However, the poor solubility of the quinalizarin in water did not allow its use in the present case. So, the reaction was tested in ethanol, methanol, acetone, DMSO and acetonitrile media. Although the highest dielectric constant of DMSO and acetonitrile, best sensitivity was achieved with methanol (Figure 2), probably because of the capacity of this solvent to form stable hydrogen bonds with the radical anion. Then, methanol was chosen for further experiments.

Maximum absorbance of the solutions was observed at $564 \mathrm{~nm}$ in methanol medium. Thus, this wavelength was chosen for all further measurements in order to obtain highest sensitivity for the method. It is important to point out that the quinalizarin alone, in methanol medium, exhibits maximum absorption at $486 \mathrm{~nm}$. The high difference between maxima of the reagent and the product absorption bands $(78 \mathrm{~nm}$ ) allowed the measurement of the product with only a small contribution of the reagent that was added in excess in the medium.

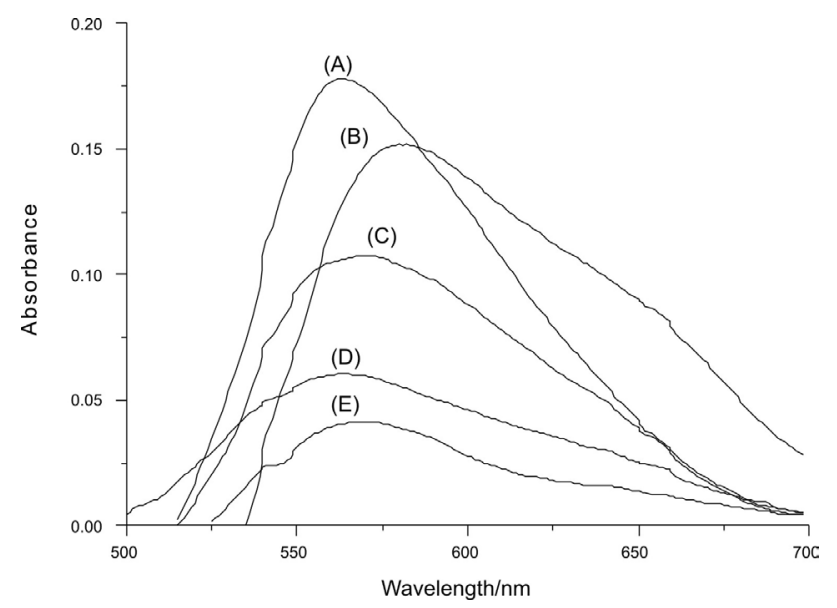

Figure 2. Spectra of solutions of quinalizarin-azithromycin in different solvents obtained against quinalizarin solutions also prepared in each solvent. (A) methanol, (B) DMSO, (C) ethanol, (D) acetonitrile and (E) acetone. Quinalizarin concentration $=30 \mathrm{mg} \mathrm{L}^{-1}$ and azithromycin concentration $=20 \mathrm{mg} \mathrm{L}^{-1}$.

\section{Effect of the quinalizarin concentration}

In spectrophotometric analytical methods where maximum sensitivity is desired, the reagent concentration in solution is an important parameter to be studied, since the maximum conversion of the analyte into absorbing specie depends on the amount of the reagent available in the solution for reaction and the equilibrium involved. In order to achieve this objective, an experiment was performed by varying the quinalizarin concentration in the range of $0-250 \mathrm{mg} \mathrm{L}^{-1}$, while the azithromycin concentration was maintained constant at $20 \mathrm{mg} \mathrm{L}^{-1}$. The results are shown in the Figure 3A. As it can be seen, remarkable increase of the absorbance at $564 \mathrm{~nm}$ was verified up to $50 \mathrm{mg} \mathrm{L}^{-1}$ quinalizarin concentration and, after this point, it only suffered a slight increase. This probably occurred because at $50 \mathrm{mg} \mathrm{L}^{-1}$ there already is a sufficient excess of the reagent to consume all azithromycin present in the medium. So, a quinalizarin concentration of $50 \mathrm{mg} \mathrm{L}^{-1}$ was established for the method to attain satisfactory sensitivity besides lower blank values.

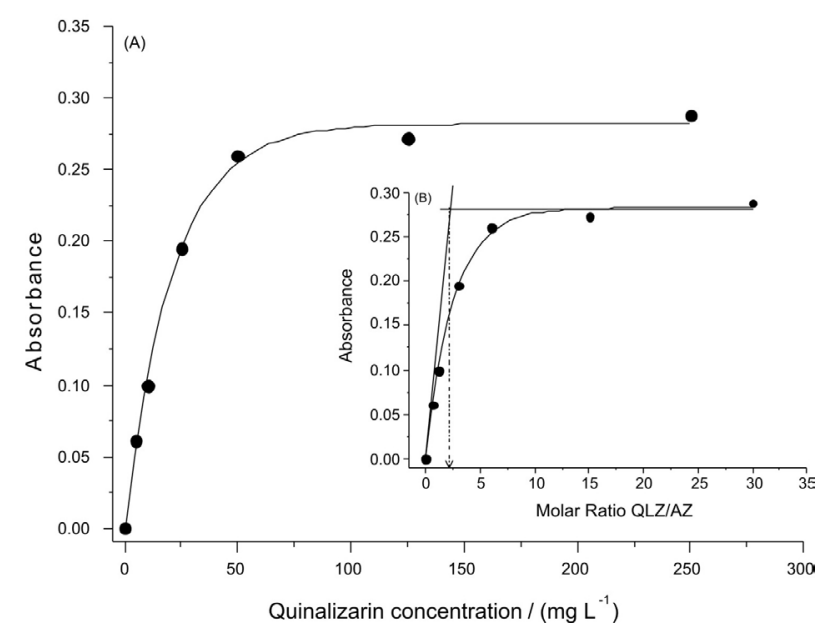

Figure 3. Effect of quinalizarin concentration on the absorbance of quinalizarin-azithromycin solutions (A). Insert (B) is the same experiment but taking into consideration the molar ratio between quinalizarin (QLZ) and azithromycin (AZ). Azithromycin concentration $=20 \mathrm{mg} \mathrm{L}^{-1}$. Absorbance measurements were carried out at $564 \mathrm{~nm}$.

It is possible to see in Figure 3B that when the quinalizarin molar concentration is twofold the azithromycin concentration there is a total consumption of the azithromycin, indicating that these reagents should react in a ratio of one mol of azithromycin for two mols of quinalizarin.

\section{Effect of the reaction time}

The optimum reaction time was determined by continuous monitoring of the absorbance at $564 \mathrm{~nm}$ of a solution containing $20 \mathrm{mg} \mathrm{L}^{-1}$ azithromicyn plus $50 \mathrm{mg} \mathrm{L}^{-1}$ quinalizarin at laboratory ambient temperature $\left(25^{\circ} \mathrm{C}\right)$. Stable absorbance values were observed from the beginning of the experiment up to $105 \mathrm{~min}$. After this time, absorbance suffered a slight increase, reaching values up to $28 \%$ higher than those observed in the beginning of the reaction. In view of these results, all measurements were carried out after $5 \mathrm{~min}$ of mixing of the reagents in order to make the method faster.

\section{Stoichiometry of the reaction}

Job's method of the continuous variation ${ }^{33}$ was employed to determine the stoichiometry of the charge transfer reaction in methanol medium. Keeping the sum of 
the molar concentrations of azithromycin and quinalizarin fixed, the ratio of the concentrations of the two substances in the mixture was varied and the absorbances of the mixtures were recorded at $564 \mathrm{~nm}$ against a convenient blank solution prepared for each point of the experiment. As shown in Figure 4, the azithromycin molar ratio which gave maximum absorbance was 0.32 , indicating that it reacts with quinalizarin in a proportion of $1: 2$ and confirming the assumption raised before when the effect of quinalizarin concentration was studied. In view of this result a reaction mechanism was proposed considering the transfer of two free electrons of the two nitrogen atoms (one electron of each nitrogen) present in one molecule of azithromycin (dimethylamine group and nitrogen in the lactone ring) to the charge-deficient center of two molecules of quinalizarin.

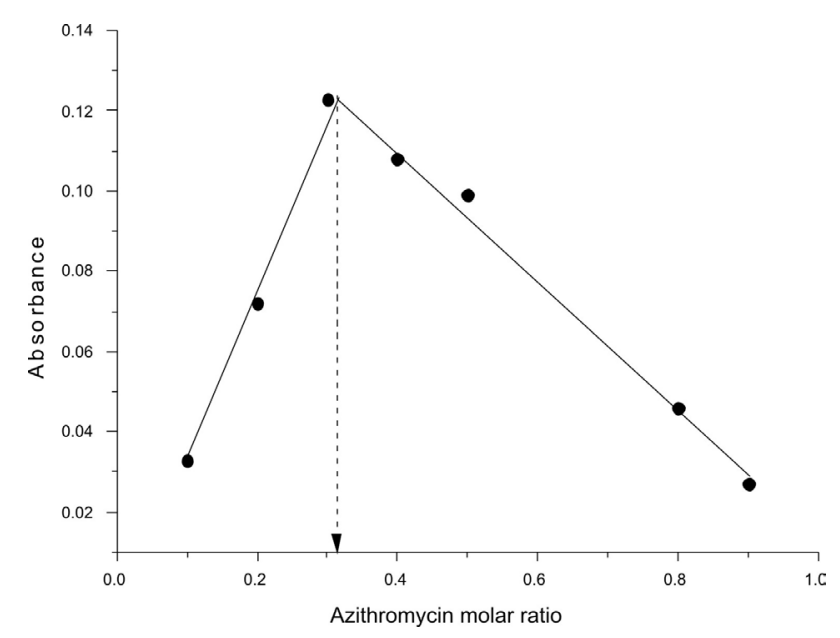

Figure 4. Application of Job's method to the reaction between quinalizarin and azithromycin. Absorbance measurements were carried out at $564 \mathrm{~nm}$.

\section{Mechanism verification}

Quinalizarin solution in methanol exhibits an absorption band with a well defined maximum at $486 \mathrm{~nm}$ while the azithromycin solution in methanol showed no absorption in the 400-700 $\mathrm{nm}$ range. The addition of azithromycin to quinalizarin solution in methanol caused an immediate change in the absorption spectrum with the appearance of a new characteristic band with maximum absorption at $564 \mathrm{~nm}$.

According to Ayad et al..$^{34}$ molecular charge-transfer complexes are formed in non-polar solvents while radical anion species are predominant in polar solvents. Also, it is believed that the addition of basic compounds that contains a lone pair of electrons, such as azithromycin, results in the formation of charge-transfer complexes of $\mathrm{n}-\pi$ type. This kind of complexes can be considered an intermediate molecular-association compound that forms a corresponding radical anion in polar solvents. In this case, radical anions results from the total transfer of charge.

In the present work, the formation of the radical anion of quinalizarin was investigated by infrared spectrometry. According to Foster, ${ }^{35}$ the decrease of specific bands in the infrared spectrum can be used to identify the site where, in the molecule, charge-transfer reaction occurs. The spectrum of the quinalizarin alone (Figure 5A) presented some specific absorption bands at 1604 and $1582 \mathrm{~cm}^{-1}$, which can be assigned to the stretching of the two $\mathrm{C}=\mathrm{O}$ bonds present in its structure. After reacting quinalizarin with azithromycin, these bands almost disappeared (Figure 5C), showing that the $\mathrm{C}=\mathrm{O}$ group was not present in the molecule anymore. This change in the spectrum evidenced the formation of a radical anion of quinalizarin from total charge transfer of the azithromycin, according to the scheme presented in the Figure 6. It is important to remark that the band located at $1724 \mathrm{~cm}^{-1}$ in the spectrum of the reaction product is due to the absorption of the $\mathrm{C}=\mathrm{O}$ group of the azithromycin (Figure 5B), which was added in excess to ensure total consumption of quinalizarin and make possible to record the spectrum of the reaction product in its absence.

\section{Interference study}

A study was performed in order to evaluate the effect of possible interferent species on the azithromycin reaction with quinalizarin. Substances usually found in the pharmaceutical formulations of azithromycin such as titanium dioxide, magnesium stearate and sodium dodecylsulfate were tested as possible interferents. Titanium dioxide and magnesium stearate were not appreciably soluble in methanol being separated from the azithromycin during filtration step. So, these substances did not present any interference on the azithromycin determination. On the other hand, SDS showed to be soluble in methanol and was then tested up to $1000 \mathrm{mg} \mathrm{L}^{-1}$ concentration. No significant variation of the analytical signal of the azithromycin was verified up to the value tested. Once this substance is found in a range of $0.5-1.0 \% \mathrm{~m} / \mathrm{m}$ in the pharmaceutical formulations and taking into account the dilution of the sample before measurement, it is possible to conclude that the SDS does not cause any remarkable interference on the determination of azithromycin in pharmaceutical formulations using the proposed method.

\section{Method evaluation}

\section{Analytical figures of merit}

The proposed methodology was critically evaluated 


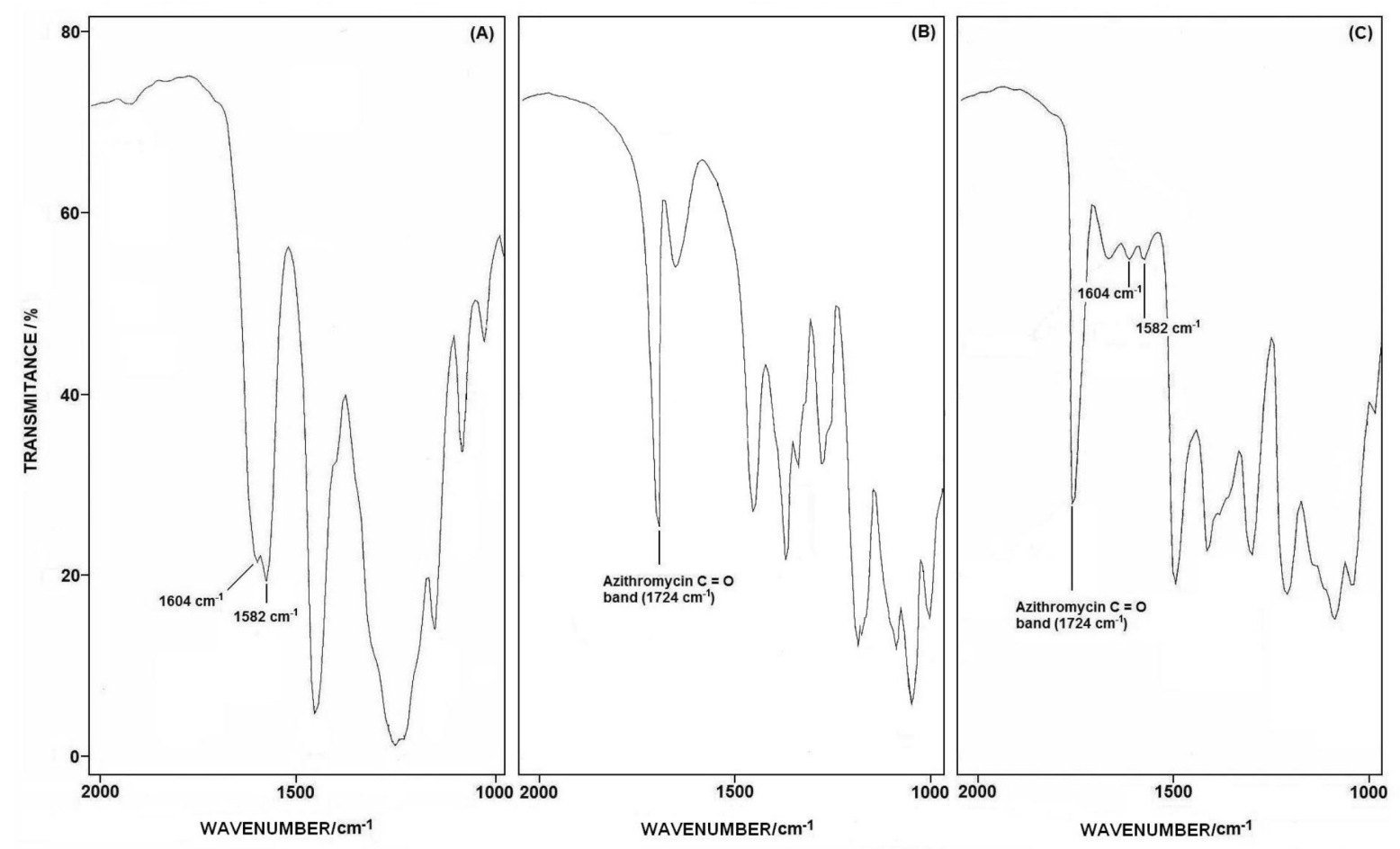

Figure 5. Infrared spectra of the quinalizarin (A), azithromycin (B) and the product of the charge transfer reaction (C).
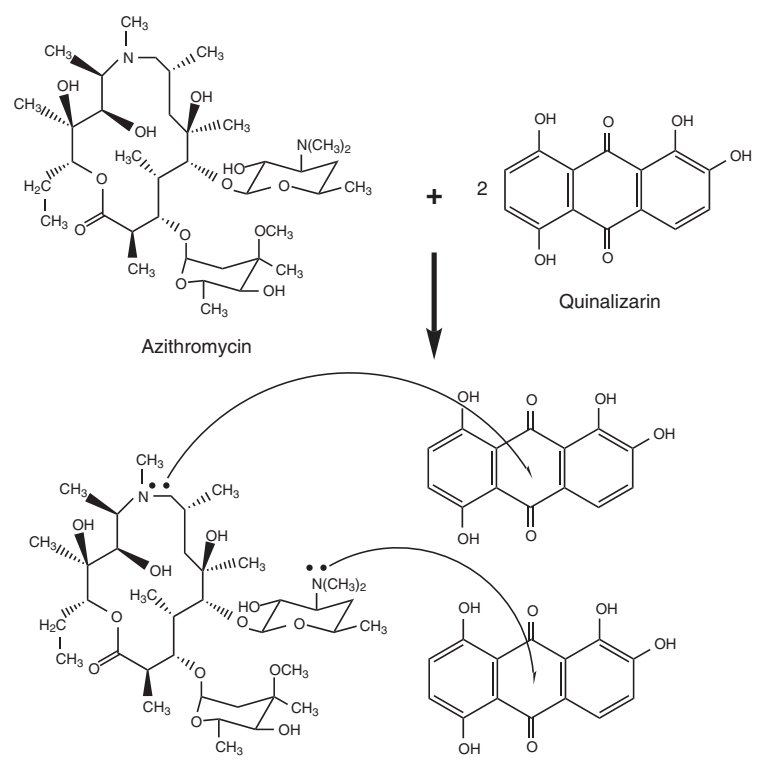

Quinalizarin - Azithromycin Complexes

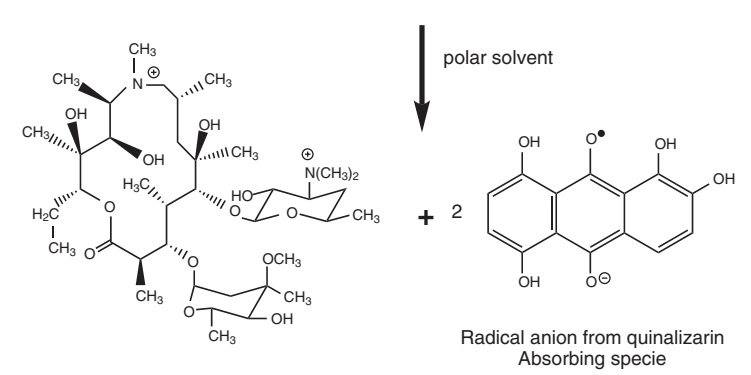

Figure 6. Possible mechanism of radical anion formation from quinalizarin and azithromycin reaction.

with regard to accuracy, precision, limit of detection, limit of quantification and linear dynamic range. Performing azithromycin determination under optimized conditions, a linear dynamic range was derived between 4 and $20 \mathrm{mg} \mathrm{L}^{-1}$, with a typical equation $\mathrm{A}=0.0134 \mathrm{C}_{\mathrm{AZ}}+0.001$ with a correlation coefficient $\mathrm{r}=0.9995$, where $\mathrm{A}$ is the absorbance and $\mathrm{C}_{\mathrm{AZ}}$ is the azithromycin concentration in $\mathrm{mg} \mathrm{L}^{-1}$. The limit of detection, estimated as three times the standard deviation of 10 independent measurements of the $4 \mathrm{mg} \mathrm{L}^{-1}$ solution was $0.35 \mathrm{mg} \mathrm{L}^{-1}$. The limit of quantification, derived from 10 times the standard deviation of the absorbance signal of the same solution was $1.2 \mathrm{mg} \mathrm{L}^{-1}$. The RSD observed was $2.95 \%$ at the $4 \mathrm{mg} \mathrm{L}^{-1}$ level.

\section{Application of the proposed method}

The applicability of the developed method was evaluated by analyzing three samples of commercial drugs containing azithromycin widely commercialized in the Brazilian market. The results obtained in the analysis are summarized in Table 1. As it can be seen, the results obtained using the proposed method agreed with the values indicated by the manufacturers, especially if the range allowed by the Brazilian pharmacopeia is taking into consideration (15\% variation). However, once the values expressed in the labels cannot be taken as reference to prove the accuracy of the method, and there are no certified materials similar to this kind of sample, the accuracy was tested by carrying out 
addition-recovery experiments. Results obtained in these experiments are shown in Table 2.

Table 1. Results obtained in the analysis of commercial pharmaceutical formulations containing azithromycin. Values are expressed as a mean \pm standard deviation $(\mathrm{n}=3)$. In all cases the reported value of azithromycin is $500 \mathrm{mg}$ per tablet

\begin{tabular}{lcc}
\hline Sample & $\begin{array}{c}\text { Azithromycin found } \\
(\mathrm{mg} \text { per tablet })\end{array}$ & Difference / (\%) \\
\hline I & $511 \pm 7.8$ & +2.2 \\
II & $494 \pm 8.2$ & -1.7 \\
III & $475 \pm 7.0$ & -5.0 \\
\hline
\end{tabular}

Table 2. Results obtained in the recovery test performed with the three samples of commercial pharmaceutical formulations containing azithromycin. Values are expressed as a mean of three independent analysis \pm standard deviation

\begin{tabular}{lccc}
\hline Sample & $\begin{array}{c}\text { Azithromycin } \\
\text { added / mg }\end{array}$ & $\begin{array}{c}\text { Azithromycin } \\
\text { recovered / mg }\end{array}$ & Recovery / (\%) \\
\hline I & 100 & $105 \pm 1.3$ & 105 \\
& 200 & $207 \pm 1.0$ & 104 \\
II & 100 & $97.8 \pm 1.9$ & 97.8 \\
& 200 & $185.6 \pm 2.5$ & 92.8 \\
III & 100 & $88.9 \pm 2.5$ & 88.9 \\
& 200 & $183.9 \pm 2.7$ & 91.9 \\
\hline
\end{tabular}

Recoveries in the range of $88.9-105 \%$ were obtained indicating that the developed method is accurate for the determination of azithromycin in commercial drugs without any matrix or spectral interferences.

\section{Conclusions}

The method proposed in the present work proved to be an excellent alternative for the azithromycin determination in pharmaceutical formulations. It presented adequate sensitivity and selectivity, allowing the determination of the analyte at levels under those found in the samples. Also, the developed method presented some advantages such as the use of low cost instrumentation (single-beam spectrophotometer) and low operational cost. In the practical point of view, the method required minimum sample treatment, which allowed us to achieve a high analytical productivity.

The charge-transfer reaction between azithromycin and quinalizarin was enhanced in methanol medium. Also, the reaction was very fast in this solvent, which allowed the absorbance measurement only 5 min after reagents mixing. Linear analytical curves were obtained in the range of 4-20 $\mathrm{mg} \mathrm{L}^{-1}$ and the limits of detection and quantification were 0.35 and $1.2 \mathrm{mg} \mathrm{L}^{-1}$, respectively. These characteristics make the method very suitable for routine analysis in quality control laboratories.

\section{Acknowledgments}

The authors would like to thank to CNPq (Conselho Nacional de Desenvolvimento Científico e Tecnológico) and CAPES (Coordenação de Aperfeiçoamento de Pessoal de Nível Superior) for financial support, grants and fellowships.

\section{References}

1. Mazzei, T.; Mini, E.; Novelli, A.; Periti, P; J. Antimicrob. Chemother. 1993, 31, 1.

2. Korolkovas, A.; Dicionário Terapêutico Gunabara, Guanabara Koogan: Rio de Janeiro, Brazil, 2006.

3. Guven, M.; Bulut, Y.; Sezer, T.; Aladag, I.; Eyibilen A.; Etikan, I.; Int. J. Pediatr. Otorhinolaringol. 2006, 70, 915.

4. Peters, D. H.; Friedel, H. A.; MacTavish, D.; Drugs 1992, 44, 750.

5. Drew, R. H.; Gallis, H. A.; Pharmacotherapy 1992, 12, 161.

6. Kinasewitz, G.; Wood, R. G.; Eur. J. Clin. Microbiol. Infect. Dis. 1991, 10, 872.

7. Chang, H. R.; Int. J. STD AIDS 1996, 7, 18.

8. McCutchan, J. A.; Int. J. STD AIDS 1996, 7, 34.

9. Leal, C.; Codony, R.; Compañó, R.; Granados, M.; Dolors-Prat, M.; J. Chromatogr., A 2004, 910, 285.

10. Kees, F.; Spangler, S.; Wellenhofer, M.; J. Chromatogr., A 1998, $812,287$.

11. Wilms, E.; Trumpie, H.; Veenendaal, W.; Touw, D.; J. Chromatogr., B 2005, 814, 37.

12. Bahrami, G.; Mohammadia, B.; J. Chromatogr., B. 2006, 830 , 355.

13. Nirogi, R. V. S.; Kandikere, V. N.; Shukla, M.; Mudigonda, K.; Maurya, S.; Boosi, R.; Yerramilli, A.; Anal. Chim. Acta 2005, $553,1$.

14. Abuin, S.; Codony, R.; Compaño, R.; Granados, M.; DolorsPrat, M.; J. Pharm. Biomed. Anal. 2005, 39, 376.

15. Zubata, P.; Ceresole, R.; Rosasco, M. A.; Pizzorno, M. T.; J. Pharm. Biomed. Anal. 2002, 27, 833.

16. Nigovic, B.; Imunic, B.S.; J. Pharm. Biomed. Anal. 2003, 32, 197.

17. Palomeque, M. E.; Ortíz, P. I.; Talanta 2007, 72, 101.

18. Khashaba, P. Y.; J. Pharm. Biomed. Anal. 2002, 27, 923.

19. Song, Z.; Wang, C.; Bioorg. Med. Chem. 2003, 11, 5375.

20. Rachidi, M.; Elharti, J.; Digua, K.; Cherrah, Y.; Boukloze, A.; Anal. Lett. 2006, 39, 1917.

21. Sultana, N.; Arayne, M. S.; Hussain, F.; Fatima, A.; Pakistan J. Sci. 2006, 19, 94.

22. Walash, M. I.; Rizk, M. S.; Eid, M. I.; Fathy, M. E.; J. AOAC Int. 2007, 90, 1579.

23. Kelani, K.; Bebawy, L. I.; Abdel-Fattah, L.; Ahamad, A. S.; Anal. Lett. 1997, 30, 1843. 
24. Huang, W.; Liu, X. J.; Zhao, F. L.; Spectrosc. Spectral Anal. 2006, 26, 913.

25. Rahman, N.; Anwar, N.; Kashif, M.; Il Farmaco 2005, 60, 605. 26. El-Mammli, M. Y.; Spectrochim. Acta, Part A 2003, 59, 771.

27. Salem, H.; J. Pharm. Biomed. Anal. 2002, $29,527$.

28. Mostafa, S.; El-Sadek, M.; Alla, E. A.; J. Pharm. Biomed. Anal. 2002, 27, 133.

29. Amin, A. S.; Ragab, G. H.; Saleh, H.; J. Pharm. Biomed. Anal. 2002, 30, 1347.

30. El-Mossalamy, E. H.; Spectrochim. Acta, Part A 2004, 60, 1161.
31. Ayad, M. M.; Shalaby, A. A.; Abdellatef, E.; Elsaid, H. M.; J. Pharm. Biomed. Anal. 1999, 18, 975.

32. Mostafa, A. A.; Bebawyb, L. I.; Refaat, H. H.; J. Pharm. Biomed. Anal. 2002, 27, 889.

33. Job, P.; Ann. Chim. 1928, 9, 113.

34. Ayad, M. A.; Belal, S.; El-Adl, S. M.; Al-Kheir, A. A.; Analyst 1984, 109, 1417.

35. Foster, R.; Organic Charge-Transfer Complexes, Academic Press: New York, 1969. 